\title{
Contemporary trends in the use of space in electroacoustic music
}

\author{
FELIPE OTONDO \\ Department of Music, University of York, York YO10 5DD, UK \\ E-mail: fo500@york.ac.uk
}

\begin{abstract}
This paper describes a survey of contemporary approaches towards the use of spatial design in electroacoustic music, focusing on the type of spatial systems used by a sample of composers and the way they conceive the use of space in their music. Comparing the results with information gathered from seventeen articles by composers written on the topic in 1997 , it is shown that composers nowadays are more used to working with different types of spatialisation systems than before. There is also a considerable increase in the use of surround 5.1 as well as four- and eight-channel systems and a decrease in the use of stereo. The compared results also show that, in general, composers nowadays seem to be less concerned with performance and interpretation issues as well as technical aspects of spatialisation. Further studies could consider a more detailed investigation of how the new spatialisation tools have shaped the aesthetical character of the music composed in recent years.
\end{abstract}

\section{INTRODUCTION}

The use of space has been an important aspect of electroacoustic music in its different forms since its early developments. The development of refined technological tools has had an impact on many of the different features of electroacoustic music, including spatialisation. As mentioned by Zvonar, it has thus shaped the aesthetics and character of the music created, allowing composers to develop new ideas with different approaches (Zvonar 2005). In the last decade there has clearly been a change in the availability of tools for spatial design for composers, mostly with cheaper sound cards (Dow 2004), powerful software with automation tools and the availability of standardised multi-channel systems such as 5.1 surround (Barbour 2002; Otondo 2005).

But how much are composers using these new tools and to what extent have these tools changed the way electroacoustic music composers conceive the use of space? With these questions in mind, the goals of this study were to investigate the types of spatialisation systems used and the approaches towards spatial design adopted by a representative group of composers nowadays, and then compare the findings with data collected from articles about this topic written almost a decade ago.

\section{SURVEY METHOD AND SAMPLE}

In order to determine which spatial systems composers use nowadays and their approaches to spatialisation with the available technology, a simple and direct survey method was designed, as will be explained below.

\subsection{Survey method}

A short questionnaire was designed consisting of two open questions. These were:

(1) In your last works, in what spatial format have you created your pieces (stereo, surround, multi-channel, other)?

(2) Can you explain some of your decisions about the use of space when you compose a piece of music?

The questionnaire was produced in three languages (English, French and Spanish), in order to allow participants to answer in the one they felt more comfortable with.

\subsection{Sample}

In order to reach a wide variety of composers, the questionnaire was sent by e-mail to different mailing lists related to electroacoustic music: the Canadian electroacoustic music (CEC) mailing list, the Sonic Arts Network (SAN) mailing list in the United Kingdom, the Dutch Electroacoustic Music mailing list, the Ars Electronica festival mailing list, and also directly to specific composers working in the field of electroacoustic music. Those composers interested in participating in the survey answered voluntarily by e-mail with their answers. The results considered for this study were gathered from replies e-mailed to the author from March 2005 to May 2006.

In total, forty-three composers answered the survey, of which $72 \%$ were European, 14\% were South American, 12\% North American and 2\% Asian. The ages of the respondents varied, most of them being composers that had been working actively in the field for at least five years. 


\section{RESULTS}

In order to facilitate the analysis of the collected data, the topics mentioned by a significant number of composers were identified as categories for analysis. In the case of question (1) the categories refer to spatial systems, and for question (2) these refer to various aspects of electroacoustic music related to sound spatialisation.

\subsection{Results for question (1)}

With regard to the spatial format in which the composers create their pieces, the results show that many composers nowadays work with more than just one spatial format and that stereo is the most popular. Table 1 shows the results for question (1) of the survey.

\subsection{Results for question (2)}

When asked to explain their decisions about the use of space, most respondents gave a quite detailed account of their approaches, describing how they conceived the use of spatialisation when composing their music. Some composers mentioned just one or two topics, while others mentioned up to five topics with abundant details. The information provided by the respondents was summarised into twelve main topics that show general tendencies towards the use of space. These topics can be seen in Table 2 in descending order from the more to the less popular.

\section{SPATIALISATION TRENDS IN 1997 AND 2006}

The original idea of this study was to compare the results obtained conducting the survey with information gathered using a similar procedure a decade ago in a straightforward way. This proved to be difficult due to the fact that there are no similar published studies that the author is aware of. For this reason, a decision was made to compare the results with data gathered from articles written in 1997 by seventeen well-established composers working in the field of electroacoustic music

Table 1. Results for question (1): In your last works, in what spatial format have you created your pieces (stereo, surround, multi-channel, other)? Note that many composers work with more than one spatial format.

\begin{tabular}{|c|c|c|c|c|c|}
\hline $\begin{array}{l}\text { Spatial } \\
\text { format }\end{array}$ & $\begin{array}{c}\text { Stereo } \\
(\%)\end{array}$ & $\begin{array}{c}\text { 8-channel } \\
(\%)\end{array}$ & $\begin{array}{c}\text { Surround } \\
5.1(\%)\end{array}$ & $\begin{array}{c}\text { 4-channel } \\
(\%)\end{array}$ & $\begin{array}{c}\text { Other } \\
(\%)\end{array}$ \\
\hline $\begin{array}{l}\text { Composers } \\
\text { that work } \\
\text { or have } \\
\text { worked } \\
\text { with this } \\
\text { format }\end{array}$ & 63 & 44 & 26 & 21 & 16 \\
\hline
\end{tabular}

Table 2. Summary of topics mentioned for question (2): Can you explain some of your decisions about the use of space when you compose a piece of music?

Topics mentioned in connection to the spatialisation of sound $(\%)$

Sound material in the composition 37

Movement of sounds

Localisation of sounds 30

Clarity of sound material

28

Musical structure

Creation of space in the composition

28

Room acoustics

23

23

21

Functional or dramatic role in the composition 21

Depth in the stereo mix

Technical issues related to software or hardware 12

Performance with live diffusion

Interpretation with live diffusion

and published by the Institute International de Musique Electroacoustique of Bourges (Barrière and Bennett 1998).

The two different types of samples in terms of age and experience as well as the different methods of obtaining the information could have had implications in the margin of error of the compared results. For this reason the compared results shown below are not treated as definitive, but rather as an indication of some global tendencies in the use of space by composers in the last decade.

\subsection{Comparing the use of spatialisation systems}

When comparing the data on the use of spatialisation systems in 1997 and 2006 one can observe that there are some shifts in tendencies, as can be seen in Table 3. Differences between the data obtained in 1997 and 2006 are shown in column 3. As one might have expected, there has been a considerable increase in the use of 5.1 surround systems, which were only starting to be available for composers in 1997. According to the compared data, in the last nine years, 5.1 surround systems have become an important spatial format for a considerable number of composers who have either created works in this format or have used it as a

Table 3. Compared results for spatial formats used by composers in 1997 and 2006.

\begin{tabular}{lrcc}
\hline Spatial format & $\begin{array}{r}1997 \\
(\%)\end{array}$ & $\begin{array}{c}2006 \\
(\%)\end{array}$ & $\begin{array}{c}\text { Difference } \\
(\%)\end{array}$ \\
\hline Surround 5.1 & 0 & 26 & 26 \\
Four-channel & 0 & 21 & 21 \\
Eight-channel & 29 & 44 & 15 \\
Other & 6 & 16 & 10 \\
Multi-channel (>eight channels) & 18 & 9 & -8 \\
Stereo & 88 & 63 & -25 \\
\hline
\end{tabular}


platform to develop more complex ideas in systems like Ambisonics (Barrett 2002; Otondo 2007). It is not clear if surround 5.1 systems will continue to be popular in the near future; there seems to be a decline already in the popularity of these systems (Richardson 2006; Field 2007).

Looking at the compared results we also find an increase in the use of four-channel systems in the last nine years. This is a slightly surprising result due to the fact that quad systems have been available for quite some time since the first performances of electroacoustic music and have led to very specific aesthetical approaches by composers in the 1970s and 1980s (Wishart 1984; Barbour 2002). This increase in popularity could be linked to the greater availability of cheaper multi-channel soundcards and software that easily allow composers to create four-channel versions of their pieces with minor changes to a stereo mix and play them in a surround 5.1 set-up dropping the central speaker channel (Otondo 2007).

We also note an increase in the use of eight-channel systems. This can be related to the greater possibilities to work with this format in multi-channel studios and concert halls nowadays, in contrast to some years ago when there were few centres that had such facilities (Vande Gorne 2002; Otondo 2007) and composers had to design their own software and hardware to work with eight or sixteen channels (Truax 1999). This increase in the popularity of eight-channel systems has also been linked to the increase in the availability of tools for spatial design by Dow (2004).

Table 3 also shows that other types of spatial systems have increased slightly in popularity, while there seems to be a slight decrease in the use of multi-channel systems with more than eight loudspeakers. The different nature of the data compared in this paper makes it difficult to know how representative of changes in approaches to spatialisation these small differences are.

Finally, we find a decrease of $25 \%$ in the use of stereo systems by composers, which could be due to the growing diversity of systems mentioned above. It seems that the new generations of composers are exposed to many more choices for spatial design, as is shown by the $37 \%$ of the respondents of the survey who said that they are using some of the other available formats instead of stereo in their recent compositions. One could speculate that the popularity of stereo systems might well increase again considering the growing importance of $\mathrm{mp} 3$ players and music heard through headphones over the Internet.

\subsection{Comparing approaches to spatialisation}

Comparing the approaches to the use of space obtained from the questionnaires with those mentioned in the articles by composers in Bourges in 1997, we can see that there are some similarities, but also substantial differences. Table 4 shows the percentage of composers that mentioned each topic in 1997 and 2006 with the respective difference arranged in descending order. At first glance, the results from the table show a tendency towards a decline in interest by composers nowadays in most of the topics compared, with larger differences at the top and bottom of the table. Due to the fact that these results might have been affected by the different nature of the samples compared, we will concentrate on these larger differences as a way to try to identify some global tendencies.

Looking at the compared results in detail, it can be observed that clarity of sound material is, surprisingly, the only topic that stands out as more important to composers in the survey in 2006 than in the 1997 articles. The details of many responses to the survey seem to indicate that composers in recent years have been using the spatialisation as a way to develop a more coherent internal space in the studio that can help to render the sound materials in the composition clearer. This seemed to be less important in 1997 when automation interface possibilities were less developed and composers had to stick to a less ambitious use of space in the studio, while

Table 4. Compared results of topics related to the use of spatialisation of sound mentioned by composers in 1997 and 2006.

\begin{tabular}{lccc}
\hline Topics related to spatialisation of sound & $1997(\%)$ & $2006(\%)$ & Difference $(\%)$ \\
\hline Clarity of sound material & 6 & 28 & 22 \\
Creation of space in the composition & 24 & 23 & -1 \\
Functional or dramatic role in the composition & 24 & 21 & -3 \\
Sound material & 41 & 37 & -4 \\
Localisation of sounds & 35 & 28 & -7 \\
Musical structure & 35 & 23 & -12 \\
Room acoustics & 35 & 21 & -14 \\
Movement of sounds & 53 & 30 & -23 \\
Depth in the stereo mix & 41 & 14 & -27 \\
Interpretation with live diffusion & 47 & 7 & -40 \\
Performance with live diffusion & 65 & 9 & -55 \\
Technical issues related to software or hardware & 71 & 12 & -59 \\
\hline
\end{tabular}


interested more in the performance possibilities of their pieces with live-diffusion in concerts.

Contrary to the positive difference for clarity of sound material, there is a tendency towards a decline for the rest of the topics compared. This difference becomes substantial, around 20-30\% less interest, for topics like movement in the composition and depth in the stereo mix. The decrease in the later topic could be related to the fact that, according to the results of the survey shown above, there are a considerable number of composers who are not working in stereo and that the possibilities of working with depth in more than two channels are still limited.

At the bottom of the table we find the range of large negative differences, between 40 and 59\%. The different character of the three topics mentioned in this range as opposed to the rest of the topics compared could be explained by the differences in approaches between composers who worked purely with stereo a decade ago and the large number of composers working with multichannel systems nowadays. Therefore, the large differences in the case of performance and interpretation through live-diffusion might be indicative of the increased popularity of surround 5.1 and standardised eight-channel systems mentioned above. The responses of many composers to the survey point to the fact that performance through live-diffusion does not seem to be as interesting as it used to be. Many respondents seem to be more interested in reproducing convincingly a spatial design developed in the studio and some feel, like Natasha Barrett, that live-diffusion can be restrictive for more detailed and complex spatial developments (Otondo 2007). Similarly, the idea of a particular interpretation of a piece from the mixing console by the composer or someone else, adding a new dimension to the spatial design done in the studio, as explained extensively by many of the composers in 1997, does not seem to be as important for the respondents in the 2006 sample. The exceptions among the latter are a few composers who have been working in this way for a long time or seem to be sceptical about reproducing in the concert hall the spatial design created in the studio, as explained by Dow (2004).

Finally, we find the largest difference of $59 \%$ for the more technical aspects of spatialisation related to hardware and software. The respondents to the survey did not seem to be very interested in technical issues related to spatialisation, but seemed to be keen to approach spatialisation from a very practical perspective, which contrasts with the detailed technical descriptions of some of the 1997 articles. In this case, the different approaches to the use of stereo or multichannel systems mentioned in the previous section seems to be directly related to the way respondents to the survey conceive the more technical aspects of spatial design as compared to almost a decade ago.

\subsection{New tools for spatial design but any new compositional approaches?}

The compared results shown above indicate in general terms a change in the approach towards spatialisation of the composers considered for this study, which can be related to the availability of new tools. However, from these results it is not clear whether there has really been an assimilation of the new technological tools leading to new compositional approaches to spatialisation. Compared results show some differences in approaches to spatialisation, but it is hard to see if there are any considerable compositional trends that one can identify. This could be related to the argument by Barrett that despite a considerable development in the technological tools available for the spatialisation of sound, this has not materialised in the electroacoustic music we hear nowadays in concerts and that 'the understanding of spatial issues among composers is still not so advanced' (Otondo 2007). Barrett considers that 'the spatialisation equipment and technology have become readily available, but the users haven't caught up' (Otondo 2007). Along the same line of Barrett's comments, but from a more technical perspective, the engineer and researcher Damian Murphy, in a recent event devoted exclusively to spatial design where commissioned pieces focusing on spatial design were premiered, said that he had been disappointed by most of the proposals received for the open call (SpaceNet 2007). In a discussion panel about spatial design closing the event he said that he identified a very conservative approach in the use of space, arguing that 'the technology is there but there has not been a development in terms of artists pushing the boundaries'.

In general terms, one could make a connection between the remarks above and the results of this study. Results show that tendencies towards the use of spatial systems seem to be much clearer than the approaches towards spatial design. It is therefore hard to see if there has been assimilation of the possibilities offered by the tools for sound space that composers are using nowadays. Further studies could consider investigating in detail to what extent specific changes in the technology for sound spatialisation identified in this study have shaped electroacoustic music aesthetically in recent years by taking specific musical examples and a more detailed survey.

\section{CONCLUSIONS}

The results of this study show a very rich and diverse picture of the contemporary use of space by a sample of electroacoustic music composers considered for the survey. Comparing the results with information gathered from articles almost a decade ago, one notes that there has been a change in the use of spatialisation systems by composers in recent years: 5.1 surround and eight-channel systems are more popular, while the 
interest in the use of stereo systems has declined. The availability of cheaper and more sophisticated spatialisation systems also seems to have affected to some extent the way composers conceive the use of space in their music. Changes in technology have made them more aware of the possibilities of reproducing the spatial design done in the studio in the concert hall and less interested in traditional stereo live diffusion performance practice. By focusing on specific examples, further studies could investigate to what extent these changes have shaped aesthetically electroacoustic music created in recent years.

\section{ACKNOWLEDGEMENTS}

The author would like to thank all the composers who kindly contributed to the survey through the Internet. This work was made possible in part by a Ph.D. grant by the Arts and Humanities Research Council (AHRC).

\section{REERENCES}

Barbour, J. 2002. Applying aural research: the aesthetics of 5.1 surround. Proc. of the Australian Computer Music Association, pp. 17-25. Melbourne.

Barrett, N. 2002. Spatio-musical composition strategies. Organised Sound 7(3): 313-23.

Barrière, F., and Bennett, G. (eds.) 1998. Composition / diffusion in electroacoustic music. In Proc. Vol. III of the Int. Academy of Electroacoustic Music. Bourges: Editions Mnemosyne.
Dow, R. 2004. Multi-channel sound in spatially rich acousmatic composition. In Proc. of the 4th Int. Conf. 'Understanding and Creating Music'. Seconda Universita de Napoli, Caserta, Italy, CD-rom.

Erickson, R. 1975. Sound Structure in Music. London: University of California Press.

Field, A. 2007. Surround Sound. Research seminar given at the Music Department of the University of York.

Otondo, F. 2005. Some considerations for spatial design and concert projection with surround 5.1. Proc. of the Digital Music Research Network Summer Conf., pp. 47-50. Glasgow.

Otondo, F. 2007. Creating spaces: an interview with Natasha Barrett. Computer Music Journal 31(2): 10-19.

Richardson, K. 2006. Tracking surround. Sound And Vision Magazine, April issue.

Spatial Audio Creative Engineering Network International Audio Workshop, Music Research Centre, Department of Music, University of York, 25 January 2007.

Truax, B. 1999. Composition and diffusion: space in sound in space. Organised Sound 3(2): 141-6.

Vande Gorne, A. 2002. L'interprétation spatiale. Essai de formalisation méthodologique. Revue DEMéter, Université de Lille-3, http://www.univ-lille3.fr/revues/demeter/ interpretation/vandegorne.pdf.

Wishart, T. 1985. On Sonic Art. York: Imagineering Press.

Zvonar, R. [n.d.] A history of spatial music. eContact! 7.4, electronic publication of the Canadian Electroacoustic Community, http://cec.concordia.ca/econtact/Multichannel/ spatial_music.html 